\author{
Asian Journal of \\ Medical and Biological Research \\ ISSN 2411-4472 (Print) 2412-5571 (Online) \\ www.ebupress.com/journal/ajmbr
}

\title{
Article \\ Conception rate following intra-cervical artificial insemination using frozen semen at field level in indigenous sheep of Bangladesh
}

\author{
Md. Abdullah Al Mansur ${ }^{1 *}$, Md. Golam Shahi Alam ${ }^{1}$, Pankaj Kumar Jha ${ }^{1,2}$, Md. Asaduzzaman Rimon ${ }^{1}$, Nazmun
} Naher ${ }^{1}$ and Farida Yeasmin Bari ${ }^{1}$

${ }^{1}$ Department of Surgery and Obstetrics, Bangladesh Agricultural University, Mymensingh, Bangladesh

${ }^{2}$ Nepal Agricultural Research Council (NARC), Khumaltar, Lalitpur, P.O. Box: 1950, Kathamndu, Nepal

Corresponding author: Md. Abdullah Al Mansur, DVM (PSTU), MS, Bangladesh Agricultural University, Mymensingh, Bangladesh, Phone: +8801723205705; E-mail: mansur_dvm@yahoo.com

Received: 04 March 2018/Accepted: 20 March 2018/ Published: 29 March 2018

\begin{abstract}
This study was undertaken to study the AI conception rate using frozen semen at field level. Five farms in Mymensingh, Bangladesh were selected for AI Trial in field ewes. Four rams were selected for semen collection, evaluation, and frozen semen production and further to study conception rate followed by intracervical AI in both natural and synchronized ewes. Conception rate were confirmed by non-returned rate and ultrasound scanning at 30-40 days of post insemination. The volume, colour, mass activity, sperm motility, viability, concentration, HOST +ve $(\%)$ and normal spermatozoa percentages were $0.8 \pm 0.3 \mathrm{ml}, 3.9 \pm 0.3,4.4 \pm 0.6$, $81.3 \pm 5.0 \%, 90.0 \pm 4.0 \%, \quad 3519.0 \pm 545.6 \times 10^{6} / \mathrm{ml}, 87.4 \pm 3.3 \%$ and $85.6 \pm 1.8 \%$, respectively. The sperm concentration of ram R\#6 was significantly higher $(\mathrm{P}<0.05)\left(4120.5 \pm 93.5 \times 10^{6} / \mathrm{ml}\right)$ compared with other rams. The mean motility and viability of pre-dilution, 120 minutes of addition of Part-A, 240 minutes of addition of Part-B and post-thaw were $(83.8 \pm 4.8 \%, 81.3 \pm 2.5 \%, 80.0 \pm 4.1 \%$ and $41.3 \pm 9.5 \%)$ and $(93.3 \pm 1.0 \%, 90.0 \pm 1.4 \%$, $88.8 \pm 1.0 \%$ and $58.3 \pm 8.7 \%)$, respectively. There were no significant difference $(\mathrm{P}>0.05)$ between pre-dilution and post-dilution sperm motility and viability percentage however, post-thaw sperm motility and viability significantly $(\mathrm{P}<0.05)$ decreased compare with the motility and viability of pre-dilution and post-dilution values. Motility and viability percentages of frozen semen did not decrease significantly $(\mathrm{P}>0.05)$ with the increase of preservation time. The mean motility and viability at $24 \mathrm{hrs}$, day 7 , day 15 and day 30 were $41.3 \pm 9.5 \%$, $41.5 \pm 8.5 \%, 41.8 \pm 9.9 \%$ and $40.5 \pm 10.2 \%$; and $59.0 \pm 10.1 \%, 58.5 \pm 7.7 \%, 59.0 \pm 8.8 \%$ and $57.8 \pm 8.3 \%$, respectively. The conception rates in natural and synchronized estrous were $26.7 \%$ and $25 \%$, respectively. There was no significant difference in conception rates between the natural and synchronized oestrous in field level. However, the present non-return rate and conception rate indicate the suitability of produced frozen semen application in the field level.
\end{abstract}

Keywords: artificial insemination; conception rate; frozen semen; sheep; HOST; Intra-cervical AI

\section{Introduction}

Sheep are important in Bangladesh, providing meat and wool. During the last twelve years sheep population increased 2.5 times, with annual growth rate of 5\% (Sarker et al., 2015). There are 3.3 million sheep (DLS, 2016), of which $32 \%$ are reared in three ecological zones. Barind, Jamuna basin and Coastal areas. Most of the sheep are indigenous, with few crossbreds (Bhuiyan, 2006) and are capable of bi-annual lambing and multiple births. The fecundity gene (Booroola) in Australian Merino may be derived from this Bengal line (Piper and Bindon, 1996). Native sheep (Ovis aries) might have originated from the wild Urial (Ovis orientalis vignei) of Asia.With the introduction of artificial insemination (AI), sheep producers in many countries are using the technologies for controlled reproduction; including synchronization of estrus, fixed-time AI, early pregnancy diagnosis and synchronization of lambing (Halbert et al., 1990; Eppleston and Maxwell, 1993; Donavan et al., 
2001). AI is practicing with the best quality rams to exploit rapid dissemination of desirable genetic merit. It is the basic assisted reproductive technique (ARTs) to inseminate and make large numbers of ewes pregnant from single ejaculation. However, insemination outcome is affected by many factors (intrinsic and extrinsic) related to female (handling, seasonality, genital morphology, etc.), male (seasonality, sperm quality, sperm conservation, etc.), farm (environmental conditions, sanitary status, handling, etc.) and the technique itself (route of application, spermatozoa/dose, technician, etc.) (Shackell et al., 1990; Donovan et al., 2004; Paulenz et al., 2005). Artificial insemination (AI) with frozen thawed semen has been proved as the most potent method for rapid genetic improvement in domestic animals. Each stage of the semen cryopreservation includes the entire process like semen collection, dilution, and equilibration and freezing. However, this technique permits limitation of the spermatozoa to lose the ability to fertilize normally (Watson, 1995). The conception rates varies (10 to $80 \%$ ) with the type of semen (fresh, freshly diluted, chilled and frozen) and AI (vaginal, cervical, intracervical, transcervical and intra-uterine) used. Conception rates with fresh semen are good (65 to $75 \%$ ) while with frozen semen (10 to 30\%) (Olesen, 1993; Gordon, 1997). In Bangladesh, some works have been performed on reproductive performances, estrus synchronization protocol, protocols for semen preservation, AI with chilled and frozen semen in DSO, BAU research station (Azizunnesa et al., 2014, 2016). However, about the use of AI is limited to research level with some initiation at farm level. The use and fruitful results of AI have drawn attention among farmers. Sheep could contribute a significant amount in livelihood promotion and in meat subsector of Bangladesh. Therefore, the present research was performed to study the AI conception rate using frozen semen at field level.

\section{Materials and Methods}

\subsection{Study area}

The cryopreservation of semen was conducted at the Reproduction Laboratory of the Department of Surgery and Obstetrics, Faculty of Veterinary Science, Bangladesh Agricultural University, Mymensingh-2202. Sheep farmer's information was taken from the district livestock officer and then five farms were visited before implementation of AI in farmer's ewes. AI trial with frozen ram semen was conducted at three farms at Trishal in Mymensingh, from January to December 2016.

\subsection{Farmers training workshop for AI trial at field level}

A day long farmers training workshop in Mymensingh was arranged for informing them the importance of AI to improve sheep breeds. Also existing sheep information from the farmers was taken.

\subsection{Animal selection for semen freezing and AI trial}

Four apparently healthy indigenous adult rams ( 2 to 2.5 years old, 20 to $22 \mathrm{~kg}$ ) were selected from the project entitled "Speed up of genetic improvement of indigenous sheep through Multiple Ovulation and Embryo Transfer (MOET) technique". Ewes $(n=23)$ were included from selected farms which were selected for AI trial. The age, parity and body weight of ewes were 1.5-3 years, 1-3 and 14-20 kg, respectively. The general health of the selected animals for this experiment was clinically examined. Both ballottement of abdomen and ultrasonography were applied to detect non pregnant ewes. The animals were reared under the field conditions on different farms. They were kept under natural field conditions, having access to good quality grasses and maintained in good health.

\subsection{Semen freezing for $A I$}

\subsubsection{Extender preparation}

Locally-manufactured extender (tris, fructose, egg-yolk: TFE) was prepared according to Azizunnesa et al. (2016); (tris-base: tris $3.4 \mathrm{~g}$, fructose $0.5 \mathrm{~g}$, citric acid $2.0 \mathrm{~g}$, penicillin 100,000 IU, strepto-mycin $100 \mathrm{mg}, 7 \%$ glycerol deionized water $100 \mathrm{~mL}$ and egg-yolk $10 \%)$.

\subsubsection{Semen collection}

Semen was collected twice in a week during the period of research (January to December 2016). Collection was always performed in the morning between 7-9 AM using properly maintained artificial vagina (AV). After collection, semen was kept at $37^{\circ} \mathrm{C}$ in water-bath until the media were added with it.

\subsubsection{Evaluation of semen}

The volume of semen was measured with a calibrated collection vial. Colour was observed visually. Sperm concentration was measured by haemocytometer method (Figure 1) (Herman and Madden, 1963). Density was 
measured observing the viscosity of sperm against the slant position of the tube. Density was scored in 4 scales; $1=$ watery, $2=$ milky, $3=$ creamy, $4=$ creamy to grainy. Sperm concentration was measured by haemocytometer method (Herman and Madden, 1963). After diluting the semen with tris (1:4) motility was determined by eyeestimation of the proportion of spermatozoa moving progressively straight forward at higher magnification $(400 \mathrm{x})$ and expressed as percentage. To evaluate the mass activity, a drop $(5 \mu \mathrm{l})$ of semen was placed on a prewarmed slide $\left(37^{\circ} \mathrm{C}\right)$ without any cover slip and examined under microscope equipped with phase-contrast optics (100x). The mass activity was scored into 5 scales: $1=$ no motion, $2=$ free spermatozoa moving without forming any waves, $3=$ small, slow moving waves, $4=$ vigorous movement with moderately rapid waves and eddies and $5=$ dense, very rapidly moving waves and distinct eddies. Viability test was performed after mixing of semen with eosin-nigrosin stain; live spermatozoa appeared unstained and dead spermatozoa stained pink against a brownish purple background (Figure 2).The sperm morphology were evaluated by using William's staining ( especially for sperm head) and buffered formol saline for acrosome, mid-piece and tail (Figure 3). Plasma membrane integrity test by hypo-osmotic swelling test (HOST) according to Ramu and Jeyendran (2013). The percentage of spermatozoa with swollen and curled tails was recorded as HOST+ve cells (Figure 4). The ram semen was preserved according to the procedure of Azizunnesa et al. (2016). Two-step dilution method was used to freeze the semen in this experiment. The frozen semen containing straws were thawed at $37^{\circ} \mathrm{C}$ for 10-15 seconds. Then post-thawed semen was placed on a clean glass slide and covered with $(18 \times 18 \mathrm{~mm})$ cover slide. The motility was determined by eye-estimation of the proportion of spermatozoa moving progressively straight forward at higher magnification $(400 \mathrm{X})$ and expressed as percentage. Also eosin-nigrosin stain was used for determining live and dead sperm percentage in frozen semen. Motility and viability percentage of frozen semen are measured at day 0 , day 7 , day 15 and day 30 .

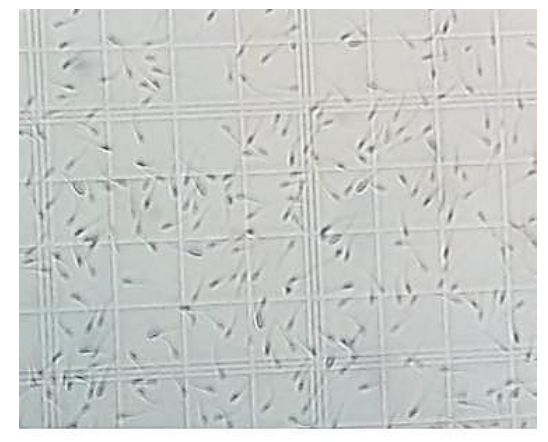

Figure 1. Sperm concentration by Haemocytometer.

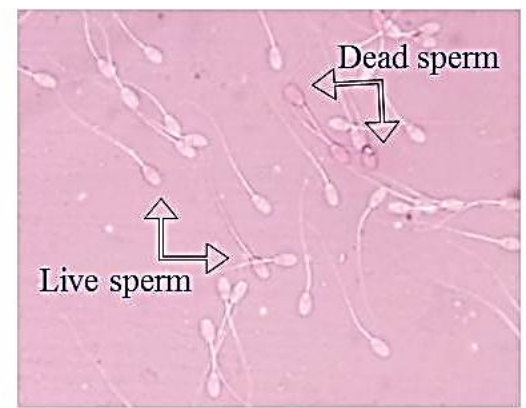

Figure 2. Viability test by Eosin-nigrosin stain.

\subsection{Estrous synchronization of farmer's ewes}

Estrus was induced in the ewes by intramuscular administration of two injections of PGF2 $\alpha$ (Ovuprost Bayer, Newzealand)@ of $150 \mu \mathrm{g}(0.6 \mathrm{ml})$ per ewe. The first injection was given ignoring the stage of the estrous cycle. After 9 days the same doses were injected to all ewes of regardless of estrus.

\subsection{Estrus detection at field level}

The onset of estrus was detected by the use of normal breeding special apron wearing ram.

The apron wearing rams were introduced in the flock after injecting PGF2 $\alpha$ intramuscularly and for a total period of 96 hours (Figure 5). 

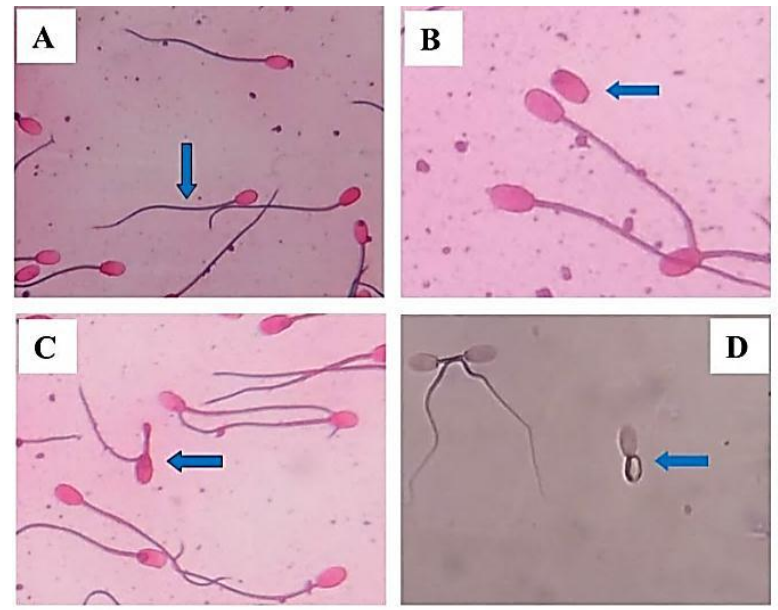

Figure 3. Sperm morphology evaluated by using William's staining method. A: Normal spermatozoa, B: Detached head C: Bent tail, D: Coiled tail

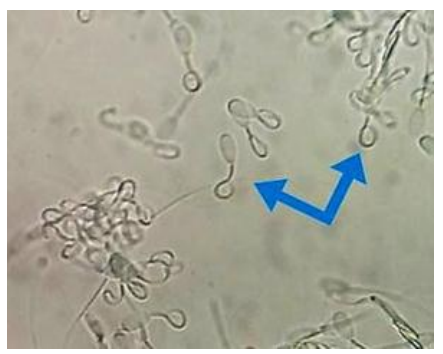

Figure 4. HOST (+ve) spermatozoa.
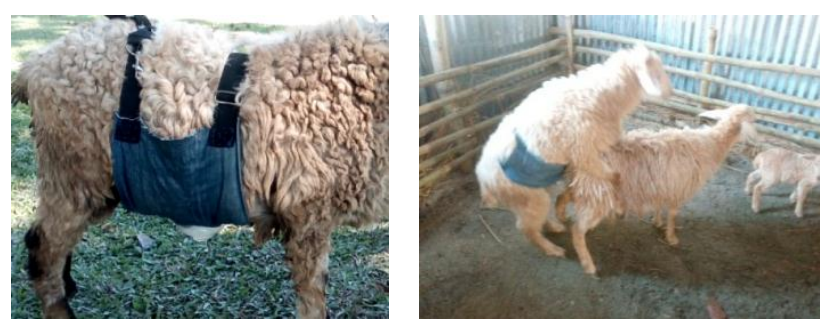

Figure 5. Ram wearing special apron and heat detection by apron wearing ram.

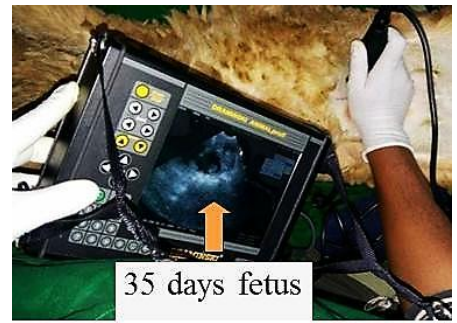

Figure 6. Pregnancy diagnosis by ultrasonography.

\subsection{Process of Intra-cervical AI (ICAI) at field level}

All natural and synchronized ewes were inseminated Intra-cervically within 14-20 hrs of 1st observed heat (Windsor et al., 1994). A standard, commercially available (eccentric insemination pipette for Sheep/Goat; Minitube, Slovakia) insemination pipette with a sharp pointed bent tip, designed for use in ewes was used for trans-cervical insemination. After thawing $0.25 \mathrm{ml}$ mini straws at $37^{\circ} \mathrm{C}$ warm water for $10-15$ seconds were dried with the help of tissue paper. Then the straw containing $200 \times 106$ spermatozoa was loaded into the AI pipette. The estrous ewes were kept in standing condition just only hind quarter up and restrained by the animal owner. Then the vulva of the ewe was cleaned with a dry paper towel and the vaginal speculum was lubricated with 
non-spermicidal water soluble lubricant (KLY $® g e l)$. The vaginal speculum was introduced into the vagina and forwarded to locate the cervix guided specialized light source for vaginal speculum. The inseminating pipette was then inserted into the cervix and pushed forward as much as it easily passes through the rings of the cervix. Then the semen was expelled deep into the cervix by pressing the plunger. After deposition of semen the pipette was kept in position for a period of 5 minutes before withdrawn from the cervix. Similar procedure was applied for insemination in all ewes.

\subsection{Pregnancy diagnosis}

All inseminated ewes were monitored for non-return to estrus by the aid of an apron wearing ram at the 17 days following insemination. The ewes which were in non-return to estrous were allowed to ultrasonographic scan for confirmation of pregnancy using trans-abdominal ultrasonography within 30-40 days of post insemination (Figure 6).

\subsection{Assumption of Non-return rate and Conception rate}

Non-return $(\mathrm{NR})$ rate $(\%)=($ Number of ewes non-return to oestrus $\mathrm{x} 100) /$ Number of ewes inseminated Conception rate $(\%)=($ Number of ewes conceived $x 100) /$ Number of ewes inseminated

\subsection{Statistical Analysis}

All values relating to semen evaluation parameters were expressed as Mean $\pm \mathrm{SD}$. The statistical analyses were done using SPSS IMB 20.0 version software program. One way analysis of variance (ANOVA) was done to find out significant differences in reproductive parameters. One-way ANOVA: Post Hoc multiple comparisons (Duncan test) were done to find out significant differences at $5 \%$ level of significance $(\mathrm{P}<0.05)$ in semen parameters. Conception rate was expressed as percentage.

\section{Results}

\subsection{Evaluation of fresh ram semen used for freezing}

The mean values of semen parameters regarding volume, color, mass activity, sperm motility, viability, concentration, HOST+ percentage and morphology percentage are shown in Table 1 . The volume, colour, mass activity, sperm motility, viability, concentration, HOST+ve(\%) and normal spermatozoa percentage varied from 0.4-1.3 ml, 2-4 (creamy to creamy-grainy), $2-5,75-92 \%, 80-95 \%, 2500-5000 \times 10^{6} / \mathrm{ml}, 75-90 \%$ and $75-95 \%$, respectively. However, their mean values were $0.8 \pm 0.3 \mathrm{ml}, 3.9 \pm 0.3,4.4 \pm 0.6,81.3 \pm 5.0 \%, 90.0 \pm 4.0 \%$, $3519.0 \pm 545.6 \times 10^{6} / \mathrm{ml}, 87.4 \pm 3.3 \%$ and $85.6 \pm 1.8 \%$, respectively. The sperm concentration of ram R\#6 was significantly higher $\left(4120.5 \pm 93.5 \times 10^{6} / \mathrm{ml}\right)$ compared with ram R\#1, R\#4 and R\#5 $\left(3496.7 \pm 125.0 \times 10^{6} / \mathrm{ml}\right.$, $2795.4 \pm 114.4 \times 10^{6} / \mathrm{ml}$ and $\left.3663.2 \pm 491.8 \times 10^{6} / \mathrm{ml}\right)$. The sperm motility of ram R\#6 and R\#5 were significantly

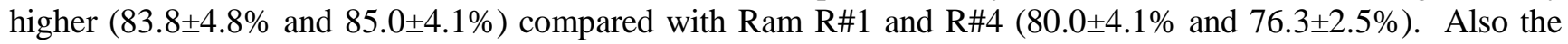
sperm viability of ram R\#6 was significantly higher $(93.3 \pm 1.0 \%)$ compared with ram R\#1, R\#4 and R\#5 $(89.3 \pm 2.8 \%, 85.0 \pm 3.6 \%$ and $92.5 \pm 1.7 \%)$. Similarly, the mass activity of ram R\#6 was significantly higher (5.0 \pm 0.0$)$ compared with ram ID R\#1, R\#4 and R\#5 ( $4.3 \pm 0.5,3.8 \pm 0.5$ and $4.8 \pm 0.5$, respectively). The plasma membrane integrity percent (HOST +ve \%) of ram R\#5 was significantly higher (90.8 $2.2 \%)$ compared with ram R\#1, R\#4 and R\#6 $(87.0 \pm 2.9 \%, 84.8 \pm 1.5 \%$ and $87.3 \pm 3.6 \%$, respectively). There was no significant difference $(\mathrm{P}>0.05)$ in semen volume and morphology \% (normal sperm \%) among the rams $(0.7 \pm 0.2,0.6 \pm 0.2$, $1.0 \pm 0.3$ and $0.9 \pm 0.2 \mathrm{ml}$, respectively) and $(84.8 \pm 1.0 \%, 85.3 \pm 1.5 \%, 87.3 \pm 1.7 \%$ and $85.3 \pm 2.2 \%$, respectively).

Table 1. Evaluation of fresh ram semen.

\begin{tabular}{lcclccccc}
\hline $\begin{array}{l}\text { Ram } \\
\text { ID: }\end{array}$ & $\begin{array}{c}\text { Volume } \\
(\mathbf{m l})\end{array}$ & $\begin{array}{c}\text { Color } \\
(\mathbf{1 - 4})\end{array}$ & $\begin{array}{l}\text { Mass } \\
\text { activity } \\
(\mathbf{1 - 5})\end{array}$ & $\begin{array}{c}\text { Sperm } \\
\text { motility } \\
(\boldsymbol{\%})\end{array}$ & $\begin{array}{c}\text { Viability } \\
(\boldsymbol{\%})\end{array}$ & $\begin{array}{c}\text { Concentration } \\
(\mathbf{x 1 0} / \mathbf{m l})\end{array}$ & $\begin{array}{c}\text { HOST } \\
(+) \mathbf{v e} \\
(\boldsymbol{\%})\end{array}$ & $\begin{array}{c}\text { Normal } \\
\text { sperms } \\
(\%)\end{array}$ \\
\hline $\begin{array}{l}\mathrm{R} \# 1 \\
(\mathrm{n}=4)\end{array}$ & $0.7 \pm 0.2^{\mathrm{a}}$ & $3.5 \pm 0.6^{\mathrm{b}}$ & $4.3 \pm 0.5^{\mathrm{bc}}$ & $80.0 \pm 4.1^{\mathrm{ab}}$ & $89.3 \pm 2.8^{\mathrm{b}}$ & $3496.7 \pm 125.0^{\mathrm{b}}$ & $87.0 \pm 2.9^{\mathrm{ab}}$ & $84.8 \pm 1.0^{\mathrm{a}}$ \\
$\begin{array}{l}\mathrm{R} \# 4 \\
(\mathrm{n}=4)\end{array}$ & $0.6 \pm 0.2^{\mathrm{a}}$ & $4.0 \pm 0.0^{\mathrm{a}}$ & $3.8 \pm 0.5^{\mathrm{c}}$ & $76.3 \pm 2.5^{\mathrm{b}}$ & $85.0 \pm 3.6^{\mathrm{c}}$ & $2795.4 \pm 114.4^{\mathrm{c}}$ & $84.8 \pm 1.5^{\mathrm{b}}$ & $85.3 \pm 1.5^{\mathrm{a}}$ \\
$\begin{array}{l}\mathrm{R} \# 5 \\
(\mathrm{n}=4)\end{array}$ & $1.0 \pm 0.3^{\mathrm{a}}$ & $4.0 \pm 0.0^{\mathrm{a}}$ & $4.8 \pm 0.5^{\mathrm{ab}}$ & $85.0 \pm 4.1^{\mathrm{a}}$ & $92.5 \pm 1.7^{\mathrm{ab}}$ & $3663.2 \pm 491.8^{\mathrm{b}}$ & $90.8 \pm 2.2^{\mathrm{a}}$ & $87.3 \pm 1.7^{\mathrm{a}}$ \\
$\begin{array}{l}\mathrm{R} \# 6 \\
(\mathrm{n}=4)\end{array}$ & $0.9 \pm 0.2^{\mathrm{a}}$ & $4.0 \pm 0.0^{\mathrm{a}}$ & $5.0 \pm 0.0^{\mathrm{a}}$ & $83.8 \pm 4.8^{\mathrm{a}}$ & $93.3 \pm 1.0^{\mathrm{a}}$ & $4120.5 \pm 93.5^{\mathrm{a}}$ & $87.3 \pm 3.6^{\mathrm{ab}}$ & $85.3 \pm 2.2^{\mathrm{a}}$ \\
Mean & $0.8 \pm 0.3$ & $3.9 \pm 0.3$ & $4.4 \pm 0.6$ & $81.3 \pm 5.0$ & $90.0 \pm 4.0$ & $3519.0 \pm 545.6$ & $87.4 \pm 3.3$ & $85.6 \pm 1.8$ \\
\hline
\end{tabular}

${ }^{\mathrm{a}-\mathrm{c}}$ The mean values with different superscript within the same column differ significantly, at least $(\mathrm{P}<0.05)$ 
3.2. Characteristics of ram semen before and after freezing used for AI

The mean values of ram semen before and after freezing have shown in Table 2.

The mean motility and viability of pre-dilution, 120 minutes of addition of Part A, 240 minutes of addition of Part-B and post thaw were $(83.8 \pm 4.8 \%, 81.3 \pm 2.5 \%, 80.0 \pm 4.1 \%$ and $41.3 \pm 9.5 \%)$ and $(93.3 \pm 1.0 \%, 90.0 \pm 1.4 \%$, $88.8 \pm 1.0 \%$ and $58.3 \pm 8.7 \%)$, respectively. There were no significant difference $(\mathrm{P}>0.05)$ in pre-dilution and post-dilution sperm motility and viability percentage. But post-thaw sperm motility $(41.3 \pm 9.5 \%)$ and viability $(58.3 \pm 8.7 \%)$ varied significantly $(\mathrm{P}<0.05)$ compared with the motility and viability of pre-dilution and postdilution.

Table 2. Characteristics of ram semen before and after freezing used for $\mathrm{AI}(\mathrm{Mean} \pm \mathrm{SD})$; $(\mathrm{n}=4)$.

\begin{tabular}{|c|c|c|c|c|}
\hline \multirow[t]{2}{*}{ Parameters } & $\begin{array}{l}\text { Pre-dilution value of ram } \\
\text { semen }(n=4)\end{array}$ & $\begin{array}{l}\text { Post-dilution } \\
\text { semen }(n=4)\end{array}$ & value of ram & \multirow{2}{*}{$\begin{array}{l}\text { Post-thawed value of } \\
\text { ram semen }(n=4)\end{array}$} \\
\hline & Fresh semen & $120 \mathrm{~min}$ & 240 min & \\
\hline Sperm motility (\%) & $83.8 \pm 4.8^{\mathrm{a}}$ & $81.3 \pm 2.5^{\mathrm{a}}$ & $80.0 \pm 4.1^{\mathrm{a}}$ & $41.3 \pm 9.5^{\mathrm{b}}$ \\
\hline Sperm viability (\%) & $93.3 \pm 1.0^{\mathrm{a}}$ & $90.0 \pm 1.4^{\mathrm{a}}$ & $88.8 \pm 1.0^{\mathrm{a}}$ & $58.3 \pm 8.7^{\mathrm{b}}$ \\
\hline
\end{tabular}

${ }^{\mathrm{a}-\mathrm{b}}$ The mean values with different superscript within the same row differ significantly, at least $(\mathrm{P}<0.05)$.

\subsection{Success of semen freezing evaluated in different preservation time}

The effects of preservation time on motility and viability of frozen semen have shown in Table 3 . Difference in Motility and viability of frozen semen was statistically non-significant ( $p>0.05$ ) with the increase of preservation time. The mean motility and viability percentages at $24 \mathrm{hrs}$, day 7 , day 15 and day 30 were $41.3 \pm 9.5 \%, 41.5 \pm 8.5 \%, 41.8 \pm 9.9 \%$ and $40.5 \pm 10.2 \%$, respectively and $59.0 \pm 10.1 \%, 58.5 \pm 7.7 \%, 59.0 \pm 8.8 \%$ and $57.8 \pm 8.3 \%$, respectively.

Table 3. Day wise Post-thaw evaluation of frozen ram semen.

\begin{tabular}{lcccc}
\hline Parameters & 24 hrs & Day 7 & Day 15 & Day 30 \\
\hline Sperm motility (\%) & $41.3 \pm 9.5$ & $41.5 \pm 8.5$ & $41.8 \pm 9.9$ & $40.5 \pm 10.2$ \\
Sperm viability (\%) & $59.0 \pm 10.1$ & $58.5 \pm 7.7$ & $59.0 \pm 8.8$ & $57.8 \pm 8.3$ \\
\hline
\end{tabular}

\subsection{Success of semen freezing observed by non-return rate and conception rate in farmers ewes}

Non-return rate (NRR) and conception rate (CR) using thawed frozen ram semen at field level have shown in Table 4. The overall NR rate was $30.4 \%$. The non-return rate following intra-cervical AI using frozen semen in natural and synchronized estrous were $33.3 \%$ and $25.0 \%$, whereas the conception rates were $26.7 \%$ and $25 \%$, respectively. The pooled over conception rate was $26.1 \%$. There was no significant difference between the natural and synchronized estrus on the conception rate using frozen semen.

Table 4. Non-return rate and conception rate at field level using thawed frozen ram semen.

\begin{tabular}{|c|c|c|c|c|c|c|}
\hline $\begin{array}{l}\text { No. of Ewes } \\
\text { inseminated }\end{array}$ & $\begin{array}{l}\text { Nature } \\
\text { estrus }\end{array}$ & $\begin{array}{l}\text { of Methods } \\
\text { of AI }\end{array}$ & $\begin{array}{l}\text { No. of ewes non } \\
\text { return to estrus }\end{array}$ & $\begin{array}{l}\text { No. of ewes } \\
\text { conceive }\end{array}$ & $\begin{array}{l}\text { Non return rate } \\
(\%)\end{array}$ & $\begin{array}{l}\text { Conception } \\
\text { rate }(\%)\end{array}$ \\
\hline 15 & Natural & ICAI & 5 & 4 & 33.3 & 26.7 \\
\hline 8 & ;ynchronized & ICAI & 2 & 2 & 25 & 25.0 \\
\hline Total $=23$ & & & 7 & 6 & 30.4 & 26.1 \\
\hline
\end{tabular}

\section{Discussion}

Four rams (4 ejaculations from each) were used to collect semen for freezing to do AI in field ewes. The volume, colour, mass activity, sperm motility, viability, concentration, HOST +ve (\%) and normal spermatozoa (\%) varied from 0.4-1.3 ml, 2-4 (creamy to creamy-grainy), 2-5, 75-92\%, 80-95\%, 2500-5000×10\% $/ \mathrm{ml}, 7590 \%$ and $75-95 \%$, respectively. Similar semen quality parameters were observed in previous study of the same laboratory (Mahmuda et al., 2015 and Azizunnesa et al., 2014). In the present study the sperm concentration of ram R\#6 was significantly higher $\left(4120.5 \pm 93.5 \times 10^{6} / \mathrm{ml}\right)$ compared with ram R\#1, R\#4 and R\#5. The mean motility of pre-dilution, 120 minutes of addition of part A, 240 minutes of addition of part B during freezing and following 24 hrs.of freezing were $83.8 \pm 4.8 \%, 81.3 \pm 2.5 \%, 80.0 \pm 4.1 \%$ and $41.3 \pm 9.5 \%$, respectively and viability 
of pre-dilution, 120 minutes of addition of part A, 240 minutes of addition of part B during freezing and following $24 \mathrm{hrs}$. of freezing were $93.3 \pm 1.0 \%, 90.0 \pm 1.4 \%, 88.8 \pm 1.0 \%$ and $58.3 \pm 8.7 \%$, respectively. There were no significant difference $(\mathrm{P}>0.05)$ between pre-dilution and post-dilution sperm motility and viability percentage. The post-thaw sperm motility $(41.3 \pm 9.5 \%)$ and viability $(58.3 \pm 8.7 \%)$ were significantly $(\mathrm{P}<0.05)$ decreased compared with the motility and viability of fresh and post-diluted semen. This result is similar with the observation of Mahmuda et al. (2015). However, the rate of motility and viability of post thawed semen in the present study were lower than observed by Azizunnesa et al. (2014). It is not clear to explain why there is difference from Azizunnesa et al. (2014), using the same protocol for freezing. This could be due to climatic condition, weather and season of the study. The mean motility of present study supported result observed with the progress of preservation time after freezing (Mahmuda et al., 2015). The success is the post thaw motility was not significantly lowered with the progress of preservation time, indicating the suitable protocol of freezing process in the present study. During freezing and thawing, the quality of spermatozoa may be affected by the composition of the cryo-extender (Leibo and Songsasen, 2002). Different extenders have different effects on freezing and thawing of semen.

Both natural oestrus and synchronized oestrous ewes were inseminated with the produced frozen thawed semen in the laboratory. The non-return to oestrus percentages in natural oestrous was $33.3 \%$, while that of synchronized oestrous was $25 \%$. Paulenz et al. (2007) reported that the average 25 -days non-return rate was $61.8 \%$, ranging between 40.0 to $82.4 \%$ in the different farms. These differences could be due to differences in breed, semen, and laboratory, skillness of AI technician and time of AI. The conception rate following insemination with frozen semen was $26.7 \%$ in natural oestrus ewes and $25 \%$ in synchronized ewes. There was no significant difference in conception rates between the natural and synchronized oestrus ewes on the conception rate using frozen semen. The number of synchronized ewes used was lower than natural ewes. The conception rate $(26.7 \%$ and $25 \%)$ in the present study was similar, higher or lower than other researchers (Olesen, 1993; Azizunnesa et al., 2014 and Kumar and Naqvi, 2014).

\section{Conclusion}

This is the preliminary application of frozen semen in the farmer's ewes. However, the present non-return rate and conception rate indicate the suitability of produced frozen semen application in the field level. Although the pregnancy rates were not in higher percentages, however, modification and refinement of present freezing technique and insemination technique may lead to higher post thaw motility and higher pregnancy rates. Work is going on in the same laboratory for obtaining the frozen semen with higher post thaw motility, leading to higher pregnancy rates that could be acceptable to the farmers, increasing and improving the sheep production in Bangladesh.

\section{Acknowledgements}

The authors are grateful to Yousuf Ali Sarker (YA Sarker) for data management and manuscript preparation. The authors are also grateful to the Bangladesh Academy of Science and United States Department of Agriculture (BAS-USDA; LS-02) for financial support.

\section{Conflict of interest}

None to declare.

\section{References}

Azizunnesa R, BF Zahora, FY Bari and MGS Alam, 2016. Comparison of commercial Triladyl extender with a tris-fructose-egg-yolk extender on the quality of frozen semen and pregnancy rate after transcervical AI in Bangladeshi indigenous sheep (Ovisaries). Small Rumin. Res., 134: 39-43.

Azizunnesa, BF Zohara, FY Bari and MGS Alam, 2014. Effects of proportion of egg yolk and preservation time on chilled semen from indigenous rams. International Journal of Veterinary Science, 1: 12-20.

BBS, 2008. Bangladesh Bureau of Statistics. Planning Division, Ministry of Planning. Government of the People's Republic of Bangladesh, Dhaka, Bangladesh.

Bhuiyan AKFH, 2006, Livestock genetic resources in Bangladesh: Preservation and Management. International conference on livestock services, Chinese Academy of Agricultural Science (CAAS), Beijing, China, April $16-20$.

Windsor DP, AZ Szell, C Buschbeck, AY Edward, JTB Milton and BC Buckrell, 1994. Transcervical artificial insemination of Australian merino eweswlth frozen-thawed semen. Theriogenology, 42:147-1 57.

DLS, 2016. Livestock Economy at a Glance 2015-2016. Directoate of Livestock Services, Bangladesh. 
Donovan A, JP Hanrahan, T Lally, MP Boland, GP Byrne, P Duffy, P Lonergan and DJO Neill, 2001. AI for sheep using frozen-thawed semen. End of Project Report ARMIS 40-47.

Donovan A, JP Hanrahan, E Kummen, P Duffy and MP Boland, 2004. Fertility in the ewe following cervical insemination with fresh or frozen-thawed semen at a natural or synchronisedoestrus. Anim. Reprod. Sci., 84: 359-368.

Eppleston J and WMC Maxwell, 1993. Recent attempts to improve the fertility of frozen ram semen inseminated into the cervix. Wool Tech. Sheep Breed, 41: 291-302.

Gordon I, 1997. Controlled Reproduction in Sheep and Goats. CAB International, 20-30.

Halbert GW, H Dobson, JS Walton, P Sharpe and BC Buckrell, 1990. Field evaluation of a technique for transcervical Intra-Uterine insemination of ewes. Theriogenology, 33: 1231-1234.

Herman, HA and FW Madden, 1963. The artificial insemination of dairy and beef cattle: A handbook and laboratory manual. Lucas Brothers, Columbia, Missouri.

Kumar D and SMK Naqvi, 2014. Effect of time and depth of insemination on fertility of Bharat Merino sheep inseminated trans-cervical with frozen-thawed semen. J. Anim. Sci. Technol., 56: 1-6.

Leibo SP and N Songsasen, 2002. Cryopreservation of gametes and embryos of non-domestic species. Theriogenology, 57: 303-326.

Mahmuda BBA, Azizunnesa, BF Zohara, MGS Alam and FY Bari, 2015. Effect of preservation time on the quality of frozen semen in indigenous rams. Bangladesh Journal of Animal Science, 44: 10-15.

Olesen I, 1993. Effects of cervical insemination with frozen semen on fertility and litter size of Norwegian sheep. Livest. Prod. Sci., 37: 169-184.

Paulenz H, T Ådnøy and L Söderquist, 2007. Comparison of fertility results after vaginal insemination using different thawing procedures and packages for frozen ram semen. Acta Veterinaria Scandinavica, 49: 26.

Paulenz H, L Soderquist, T Adnoy, AB Nordstoga, M Andersen and K Berg, 2005. Effect of vaginal and cervical deposition of semen on the fertility of sheep inseminated with frozen thawed semen. Vet. Rec., 156: $372-375$.

Piper LR and BM Bindon,1996. The Boroola Merino. In Prolific Sheep, Fahmy MH (Eds.), CAB International, Wallingford, United Kingdom, pp. 152-160.

Ramu S and RS Jeyendran, 2013. The hypo-osmotic swelling test for evaluation of sperm membrane integrity. Methods Mol. Biol., 927: 21-25.

Sarker YA, AH Miah, N Sharif, MH Himel, S Islam, RC Ray, TK Paul, MT Islam and MH Sikder, 2015. A retrospective study of common diseases at veterinary teachinghospital, Bangladesh Agricultural University, Mymensingh. Bangl. J. Vet. Med., 13:55-61.

Shackell GH, B Kyle, RP Littlejohn, 1990. Factors influencing the success of a large scale artificial insemination programme in sheep. Proceedings of the New Zealand Society of Animal Production, 50: 427430.

Watson PF, 1995. Recent developments and concepts in the cryopreservation of spermatozoa and the assessment of their post-thawing functions. Reprod. Fertil. Dev., 7: 871-891. 